\title{
Simultaneous observations of convective gravity waves from a ground-based airglow imager and the AIRS satellite experiment
}

\author{
Jia Yue, ${ }^{1}$ Lars Hoffmann, ${ }^{2}$ and M. Joan Alexander ${ }^{3}$ \\ Received 15 November 2012; revised 18 February 2013; accepted 16 March 2013; published 25 April 2013.
}

[1] We report the first joint observations of convectively generated gravity waves (GWs) using an $\mathrm{OH}$ airglow imager in Colorado and the Atmospheric Infrared Sounder (AIRS) onboard the Aqua satellite. Convective GWs, appearing as concentric rings, are observed over the western Great Plain regions of North America in the evening of 3 June 2008 in the airglow images. Inspecting both weather radars and AIRS radiances at $8.1 \mu \mathrm{m}$, strong convective clouds are found near the center of the concentric rings. The AIRS data at $4.3 \mu \mathrm{m}$ show semicircular GWs with horizontal wavelengths of 60-80 km at $0900 \mathrm{UT}$, whereas the airglow imager observed circular GWs with horizontal wavelengths of $\sim 44 \mathrm{~km}$ and airglow emission perturbation of $\sim 6 \%$ at the same geographic location at 0910 UT. Large-scale GWs (horizontal wavelengths greater than $100 \mathrm{~km}$ ) emanating northwestward can be seen in both AIRS data and airglow images at different times. The imager observed small-scale ripples associated with unstable concentric GWs in the mesopause in the early evening. Given that the brightness temperature perturbation of the GWs in the AIRS data is about $0.16 \mathrm{~K}$ and assuming that the GWs propagate without dissipation from the stratosphere to the upper mesosphere, the expected airglow emission perturbation caused by the GWs would be $4 \%-17 \%$. Ray tracing simulations are performed to demonstrate that the GWs seen in AIRS and in the imager were likely excited by the same convective system.

Citation: Yue, J., L. Hoffmann, and M. Joan Alexander (2013), Simultaneous observations of convective gravity waves from a ground-based airglow imager and the AIRS satellite experiment, J. Geophys. Res. Atmos., 118, 3178-3191, doi:10.1002/jgrd.50341.

\section{Introduction}

[2] It is commonly recognized that deep convection is a significant source for atmospheric gravity waves (GWs) [e.g., Fritts and Alexander, 2003]. Convectively generated GWs in the tropics and at midlatitudes are of great importance for the momentum budget of the middle atmosphere circulation and composition [e.g., Holton, 1982; Alexander and Rosenlof, 1996; Richter et al., 2010]. Within a convective system, both diabatic forcing (latent heating and cooling) and overshooting at the tropopause can excite a broad spectrum of GWs on various temporal and spatial scales [Lane et al., 2001]. While emanating away from their sources, wave packets spread out horizontally and vertically governed by the GW's dispersion relation. Wave components with high frequencies (or short periods) propagate more vertically than those with longer periods [Fritts and Alexander, 2003]. GWs with slower vertical group velocities reach the middle atmosphere later than those with faster velocities. Hence,

\footnotetext{
${ }^{1}$ Atmospheric and Planetary Science, Hampton University, Virginia, USA.

${ }^{2}$ Jülich Supercomputing Centre, Forschungszentrum Juelich, Juelich, Germany.

${ }^{3}$ NorthWest Research Associates, Boulder, Colorado, USA.

Corresponding author: J. Yue, Atmospheric and Planetary Science, Hampton University, 23 Tyler Street Hampton, VA 23668, USA. (jia.yue@hamptonu.edu)

(C)2013. American Geophysical Union. All Rights Reserved. 2169-897X/13/10.1002/jgrd.50341
}

convectively generated GWs display as a spatial distribution in the vertical cross-sections of temperature, pressure, and winds [Alexander et al., 1995; Piani et al., 2000]. They are also viewed as a group of outwardly expanding concentric rings on the horizontal plane with the center located near the convective source [e.g., Taylor and Hapgood, 1988; Dewan et al., 1998; Sentman et al., 2003; Yue et al., 2009; Vadas et al., 2009; Grimsdell et al., 2010]. If the intervening winds between the tropopause and mesopause are weak, the GWs can penetrate into the middle atmosphere and break near the mesopause $(80-100 \mathrm{~km})$ [Horinouchi et al., 2002]. As a result, the $\mathrm{OH}, \mathrm{OI}$, and $\mathrm{Na}$ airglow emissions near the mesopause can be modulated by these GWs and form concentric ring patterns observed using the multispectral airglow imagers.

[3] There is a long history of observing convectively generated concentric GWs in mesospheric airglow layers using ground-based cameras or imagers. Taylor and Hapgood [1988] first identified the source of concentric rings in mesopause nightglow emissions to be due to convective GWs triggered by an isolated thunderstorm in France. Suzuki et al. [2007] observed concentric wave patterns in both the OI (557.7 nm) and infrared $\mathrm{OH}$ Meinel bands. A cumulonimbus cloud was found in a satellite image near the center of these concentric GWs. The Great Plains region of the United States is an ideal place to observe such type of GWs. Sentman et al. [2003] simultaneously observed concentric GWs in $\mathrm{OH}$ airglow emissions and sprites using a high-speed CCD camera. Using an all-sky airglow imager at the Yucca Ridge Field Station (YRFS) $\left(40.7^{\circ} \mathrm{N}, 104.9^{\circ} \mathrm{W}\right)$ in Colorado, Yue 
et al. [2009] reported nine concentric GW events in the $\mathrm{OH}$ layer $(\sim 87 \mathrm{~km})$ that occurred between 2003 and 2008. Detailed comparisons between the airglow observations of concentric GWs in Colorado and 3-D ray tracing simulations have been performed by Vadas et al. [2009, 2012].

[4] Dewan et al. [1998] using data from the Midcourse Space Experiment reported the first observations of convectively generated GWs from space. The weighting functions of the nadir observations in the $4.3 \mathrm{CO}_{2} \mu \mathrm{m}$ fundamental band peak at a height of $\sim 35 \mathrm{~km}$. The radiance measurements are most sensitive to temperature perturbations at these altitudes. Dewan et al. [1998] also showed that convective clouds in the tropics closely coincide with the centers of concentric wave patterns. Since 2002, the Atmospheric Infrared Sounder (AIRS) [Aumann et al., 2003] onboard NASA's Aqua satellite measures thermal emissions of the atmosphere in the nadir and sublimb observation geometry. Radiance measurements at 4.3 and $15 \mu \mathrm{m}$ are used to detect GWs in the stratosphere [e.g., Hecht et al., 2009; Kim et al., 2009; Hoffmann and Alexander, 2009, 2010; Grimsdell et al., 2010]. The concentric semicircular patterns seen in the Midcourse Space Experiment and AIRS images resemble those from the airglow imagers and numerical simulations [Kim et al., 2009; Grimsdell et al., 2010].

[5] In this paper, we report the first joint observations of concentric GWs in both the YRFS ground-based $\mathrm{OH}$ airglow images and space-borne AIRS data. Although the GWs are independently observed in the stratosphere and at the mesopause by two different remote sensing techniques with different measurement geometries, the concentric semicircular patterns found in both observations closely resemble each other. Joint observations with multiple instruments and techniques cover a broader spectrum of convective GWs than those with a single technique, leading to a more comprehensive understanding of the excitation, propagation, and dissipation of GWs.

\section{Methods and Characteristics of Observations}

\subsection{Yucca Ridge Field Station Airglow Imager}

[6] The all-sky camera at YRFS, Colorado, is sensitive to emissions from the $\mathrm{OH}$ Meinel bands between $795 \mathrm{~nm}$ and $1 \mu \mathrm{m}$ from the $\mathrm{OH}$ layer $(\sim 87 \mathrm{~km})$ [Nakamura et al., 2005]. The imager was in operation between 2003 and 2008. It acquired one image with $512 \times 512$ pixels every $2 \mathrm{~min}$. Altogether nine mesospheric concentric GW events were reported along with their estimated convective sources and background winds [Yue et al., 2009]. Among these is the 3 June 2008 event, which will be discussed in more detail in this paper.

[7] Weather permitting, the camera continuously monitors the airglow emissions for multiple hours during nighttime. As a result, wave periods $\tau$ and horizontal phase velocities $c_{h}$ can be measured by following the wavefronts. The high temporal resolution $(2 \mathrm{~min})$ and high horizontal resolution $(\approx 0.5 \mathrm{~km}$ at zenith) allow resolution of GWs with periods of several minutes and horizontal wavelengths $\lambda_{h}$ of a few kilometers. The vertical wavelength $\lambda_{z}=2 \pi / m$ can be derived using the GW anelastic dispersion relation [Fritts and Alexander, 2003], with background temperature and wind known,

$$
m^{2}=\frac{N^{2}}{\left(c_{h}-U_{h}\right)^{2}}-k_{h}^{2}-\frac{1}{4 H^{2}}
$$

where $m$ is the vertical wave number, $N$ is the Brunt-Vaisala frequency, $U_{h}$ is the background horizontal wind in the wave propagation direction, $H \approx 7 \mathrm{~km}$ is the scale height, $k_{h}=2 \pi / \lambda_{h}$ is the horizontal wavenumber.

[8] A single all-sky camera covers a horizontal area of up to $1000 \mathrm{~km}$ diameter in the mesopause region. Therefore, large-scale GWs with wavelengths longer than $200 \mathrm{~km}$ are difficult to detect by a single all-sky imager. Moreover, because the $\mathrm{OH}$ layer is $\sim 10 \mathrm{~km}$ thick, GW perturbations with short vertical wavelengths in the airglow emissions are cancelled out [Liu and Swenson, 2003].

[9] One weakness of the ground-based imager to observe convectively generated GWs is that the imager's field of view (FOV) is often blocked by the clouds within the same convective system that excites the GWs. The west side of the North American Great Plains (Colorado, Wyoming, Kansas, Nebraska, New Mexico, and South Dakota) is deemed to be an ideal location to observe concentric GWs [Sentman et al., 2003; Yue et al., 2009; Vadas et al., 2012]. The tropospheric winds tend to be westerly and blow the convective clouds eastward away from the YRFS, which is on the east side of the Rocky Mountains. Hence, there is a relatively high chance to have a clear sky right above the camera and simultaneously encounter strong thunderstorms to the east. Concentric GWs are very rarely observed from ground-based airglow imagers at other geographical locations. Imagers installed on the aircraft or spacecraft can fly over the clouds and overcome this disadvantage [e.g., Mende et al., 1998], but their observation periods are often limited.

\subsection{Atmospheric Infrared Sounder Observations}

[10] The NASA Aqua satellite was launched in May 2002. It operates in a Sun-synchronous, near polar orbit $(705 \mathrm{~km}$ altitude, $99 \mathrm{~min}$ period, $98.2^{\circ}$ inclination). Mesoscale stratospheric GWs can be detected directly in AIRS radiance measurements [e.g., Alexander and Teitelbaum, 2007; Eckermann et al., 2007; Hoffmann and Alexander, 2009, 2010; Gong et al., 2012]. Both the $4.3 \mu \mathrm{m}$ and $15 \mu \mathrm{m} \mathrm{CO}_{2}$ fundamental bands can be utilized for this purpose. Typically, the $4.3 \mu \mathrm{m}$ radiances are more sensitive to temperature perturbations because the Planck function is more sensitive at shorter wavelengths. In this paper the AIRS radiance data are reported as brightness temperatures, which are obtained by inserting the measured radiances in the inverse Planck function. The brightness temperatures should not be confused with direct measurements of atmospheric temperature. Averaging radiance data from multiple AIRS channels with similar characteristics in terms of temperature weighting functions helps to reduce measurement noise and to improve the chance of detection of GWs with short vertical wavelengths. A set of 42 AIRS channels at $4.3 \mu \mathrm{m}$ that are ideally suited for GW analysis is depicted by Hoffmann and Alexander [2010]. The weighting functions of these channels show sensitivity to atmospheric temperature from 20 to $60 \mathrm{~km}$ altitude, with maximum sensitivity around 30 to $40 \mathrm{~km}$. With these channels, the AIRS experiment can detect stratospheric GWs with vertical wavelengths longer than $\sim 20 \mathrm{~km}$ and horizontal wavelengths ranging from 50 to $1000 \mathrm{~km}$. The airglow imager is more suitable to observe small-scale GWs, whereas AIRS is more sensitive to large-scale GWs. 
Table 1. The Spectrum Range of GWs Measurable by AIRS and the YRFS OH Airglow Imager

\begin{tabular}{lcc}
\hline & YRFS OH Imager & $\begin{array}{c}\text { AIRS } 4.3 \mu \mathrm{m} \\
\text { Radiances }\end{array}$ \\
\hline Horizontal wavelength $[\mathrm{km}]$ & $2-200 \mathrm{~km}$ & $50-1000 \mathrm{~km}$ \\
Vertical wavelength $[\mathrm{km}]$ & $>10 \mathrm{~km}$ & $>20 \mathrm{~km}$ \\
Temporal coverage & 2 min interval (continuous & Two \\
& observation during night) & overpasses \\
Period [min] & $>4$ min & per day \\
\hline
\end{tabular}

[11] The Aqua satellite passes the Great Plains twice a day; the ascending orbits occur during the daytime (about 1330 LT), the descending orbits occur at night (about 0130LT). Without higher temporal resolution, the AIRS radiances can only be used to measure the horizontal wavelength $\lambda_{h}$, but cannot resolve the wave period $\tau$ and phase velocity $c_{h}$. Thus, the vertical wavelength $\lambda_{z}$ cannot be obtained based on equation (1) with only the horizontal wavelength known. The GW spectra detectable by AIRS and the YRFS OH airglow imager are summarized in Table 1.

[12] From space, the detection of stratospheric GWs is not hindered by clouds. Thus, the chance to detect GWs over the North American Great Plains by AIRS is much higher (8 $\pm 3 \%$ from May to August during 2003-2008 [Hoffmann and Alexander, 2010]) than that using the ground-based camera ( 9 events out of 723 clear nights in 2003-2008 or $1.2 \%$ [Yue et al., 2009]). Figure 1 shows a schematic of the geometry of AIRS and the airglow imager observing the convective GWs. In this study, we combine the two remote sensing methods to try to shed new light on the nature of convective GWs.

\subsection{Observations of Convection by NEXRAD Radars and AIRS}

[13] The Next-Generation Radar (NEXRAD) is a network of S-band Doppler radars in the United States operated by the National Weather Service under the NOAA. The NEXRAD measures both precipitation (precipitation mode) and wind (clear-air mode). The NEXRAD echo maps have been used by Yue et al. [2009] and Vadas et al. [2012] to search for overshooting plumes that excited GWs observed by the YRFS imager. During the thunderstorms relevant to this study, the NEXRAD was in precipitation mode. The S-band radars provide reflectivity data at $1 \mathrm{~km}$ by 1 degree to $460 \mathrm{~km}$ range. To identify deep convective plumes, we search for strong reflectivities ( $>18.5 \mathrm{dBZ})$ [e.g., Vadas et al., 2012].

[14] High, cold clouds related to deep convection in the tropics or mesoscale convective systems at mid latitudes can be identified in IR satellite imagery based on low brightness temperatures in spectral window regions. Aumann et al. [2006] used the $1231 \mathrm{~cm}^{-1}$ AIRS radiance channel $(8.1 \mu \mathrm{m})$ and a temperature threshold of $210 \mathrm{~K}$ to identify deep convection in equatorial regions. In this spectral region, the atmosphere is nearly transparent. Without clouds, this channel detects warm surface emissions. A brightness

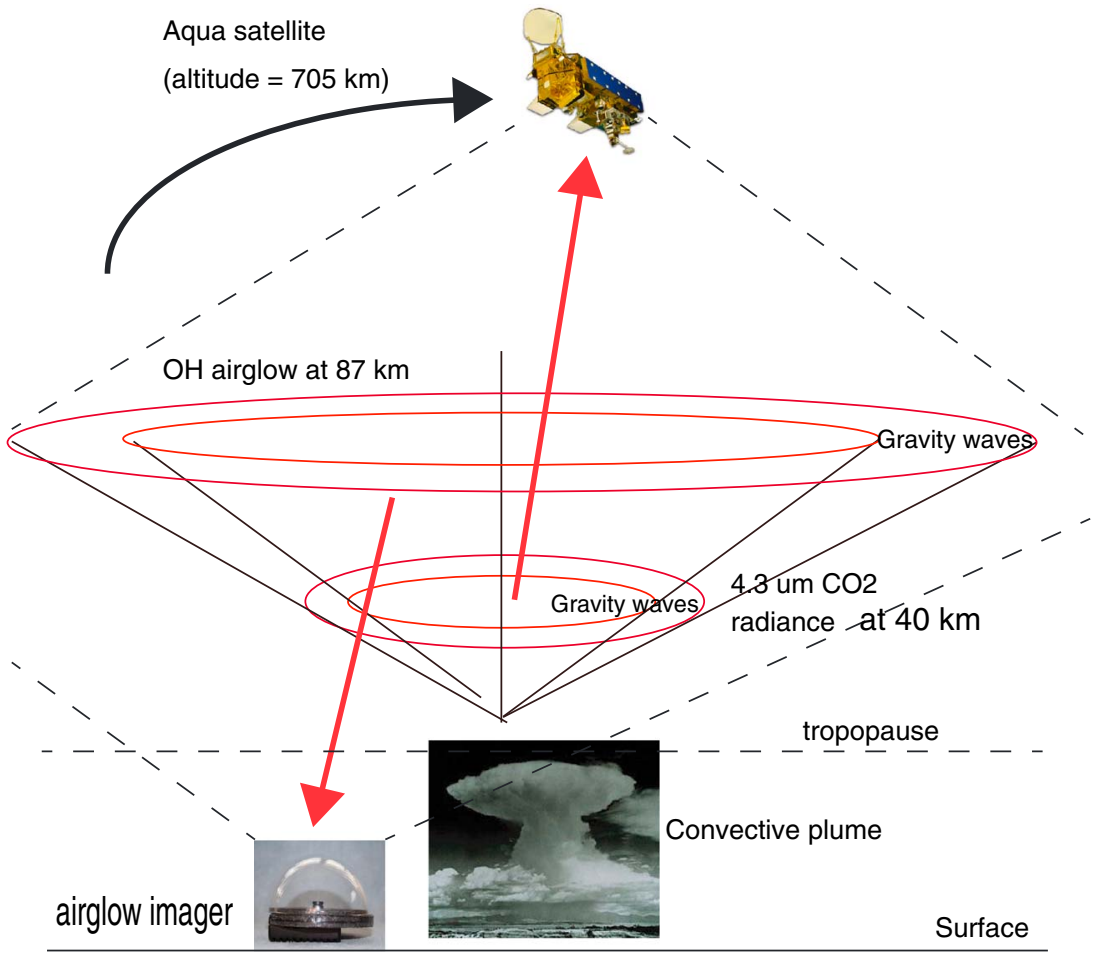

Figure 1. Observational geometry of the AIRS and ground-based all-sky airglow imager measurements of the convectively generated GWs. The picture of the cumulonimbus is taken from http://en.wikipedia. org/wiki/Cumulonimbus_cloud. The picture of the Aqua platform is from http://nsidc.org/data/docs/ daac/aqua platform.gd.html. The horizontal lines denote the Earth's surface (solid line) and the tropopause (dashed line). The slanted dashed lines indicate the field of views for the airglow imager and AIRS instrument. The slanted solid lines show the wave fronts. 


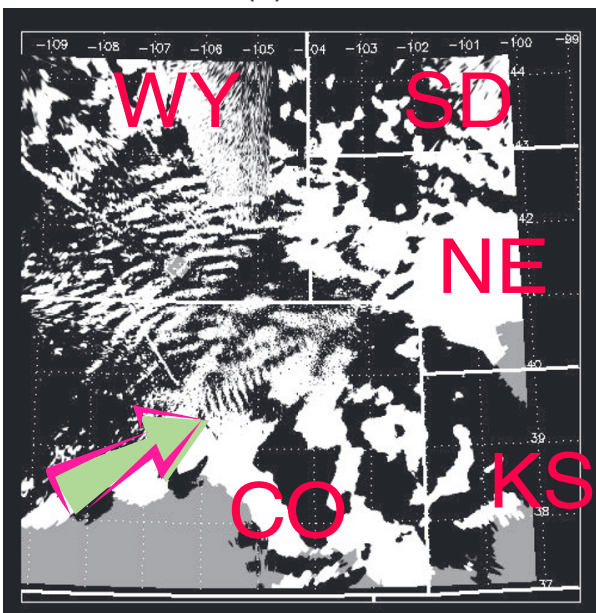

(c) 0800 UT

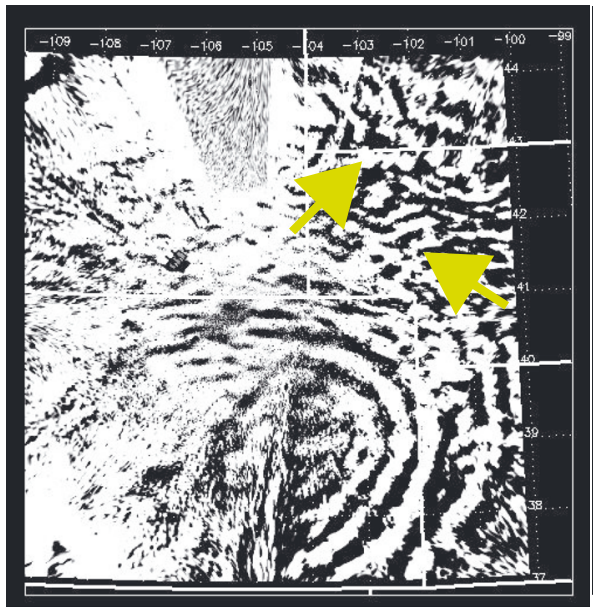

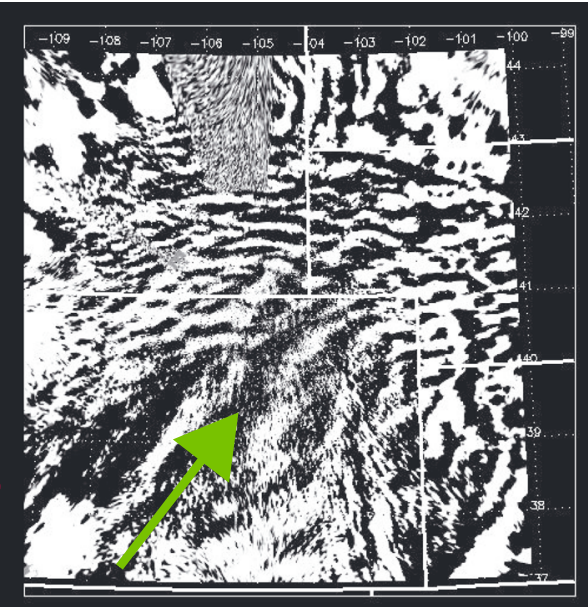

(d) 0910 UT

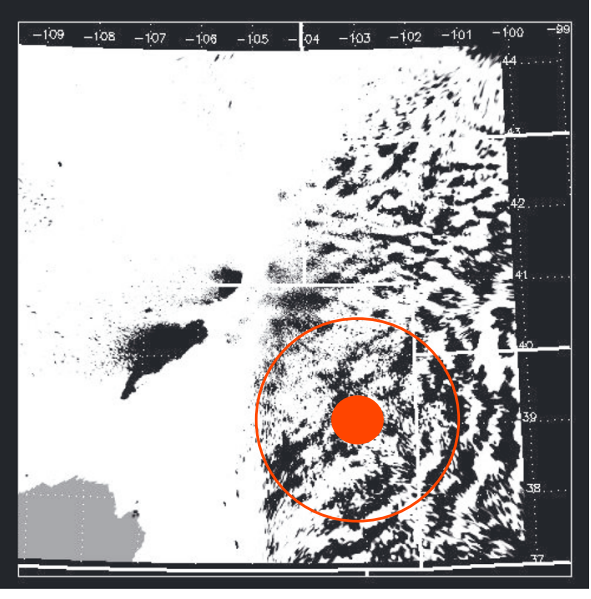

Figure 2. Difference images of $\mathrm{OH}$ airglow emissions from 0500 to 0910 UT on 3 June 2008 over the North American Great Plains. The white line indicates the state borders between Colorado (CO), Nebraska (NE), South Dakota (SD), Kansas (KS), and Wyoming (WY). The images cover an area of $800 \mathrm{~km} \times 800 \mathrm{~km}$, ranging from $110^{\circ} \mathrm{W}$ to $100^{\circ} \mathrm{W}$ and $37^{\circ} \mathrm{N}-44^{\circ} \mathrm{N}$. The horizontal resolution is $\sim 0.5 \mathrm{~km}$. Arrows indicate different GW events (for details see text). Estimated convective source before 0900 UT is marked by a red dot. A distance of $200 \mathrm{~km}$ from the red dot is denoted as a red circle.

temperature colder than the tropopause temperature indicates overshooting by an uprising convective plume. Hoffmann and Alexander [2010] raised the $210 \mathrm{~K}$ threshold of Aumann et al. [2006] to $220 \mathrm{~K}$ to be able to detect deep convection at mid latitudes.

\section{Observations on 3 June 2008}

\subsection{Airglow Imager Observations of Mesospheric Gravity Waves}

[15] Among those nine concentric GW events from the YRFS imager observations from 2003 to 2008 [Yue et al., 2009], semicircular concentric GW patterns can be found also in the AIRS data on 3 June 2008 around 0900 UT. A snapshot of the 3 June $2008 \mathrm{GW}$ event is displayed in Figure 2 of Yue et al. [2009]. In this paper this event is discussed in more detail. The YRFS imager started to see concentric GWs after 5 UT and stopped operation at 0950 UT before dawn. A sequence of flattened and differenced
$\mathrm{OH}$ airglow images at an interval of approximately one hour is displayed in Figure 2. The image processing to obtain the unwrapped differenced images from the raw $\mathrm{OH}$ airglow measurements is described in Yue et al. [2009].

[16] At $\sim 0500$ UT (Figure 2a), we can see concentric GWs expanding northwestward over Wyoming and northern Colorado with horizontal wavelengths of 17-22 km and a phase velocity of approximately $70 \mathrm{~m} / \mathrm{s}$. Clouds block a large portion of the image in the southeast corner. In addition, small-scale ripples perpendicular to the wavefronts are clearly seen near the center of the imager FOV (denoted by the green arrow). These ripples have very small horizontal wavelengths of $8-13 \mathrm{~km}$. These ripples indicate that either dynamic or convective instability takes place, which is associated with GW breaking events [e.g., Hecht, 2004; Yue et al., 2010]. Without concurrent wind and temperature measurements during this night, we are unable to determine whether these ripples are caused by dynamic instability (indicated by Richardson number $<1 / 4$ ) or convective 


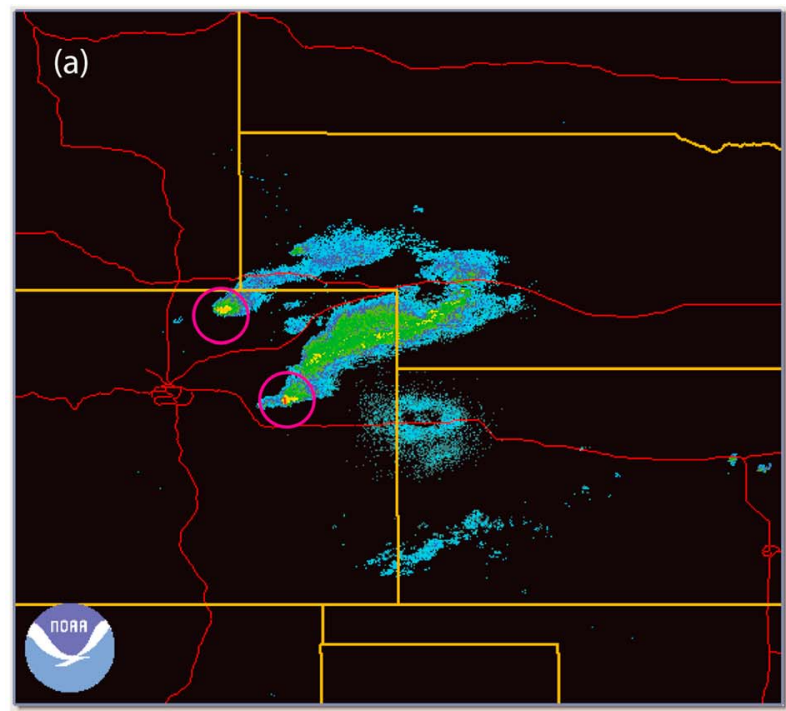

NEXRAD LEVEL-II KGLD - GOODLAND, KS 05/03/2008 04:28:33 GMT LAT: $39 / 22 / 00 \mathrm{~N}$ LON: $101 / 42 / 01 \mathrm{~W}$ ELEV: $3652 \mathrm{FT}$ VCP: 212

REFLECTIVITY ELEV ANGLE: 1.37

Legend: $d B Z$ (Category)
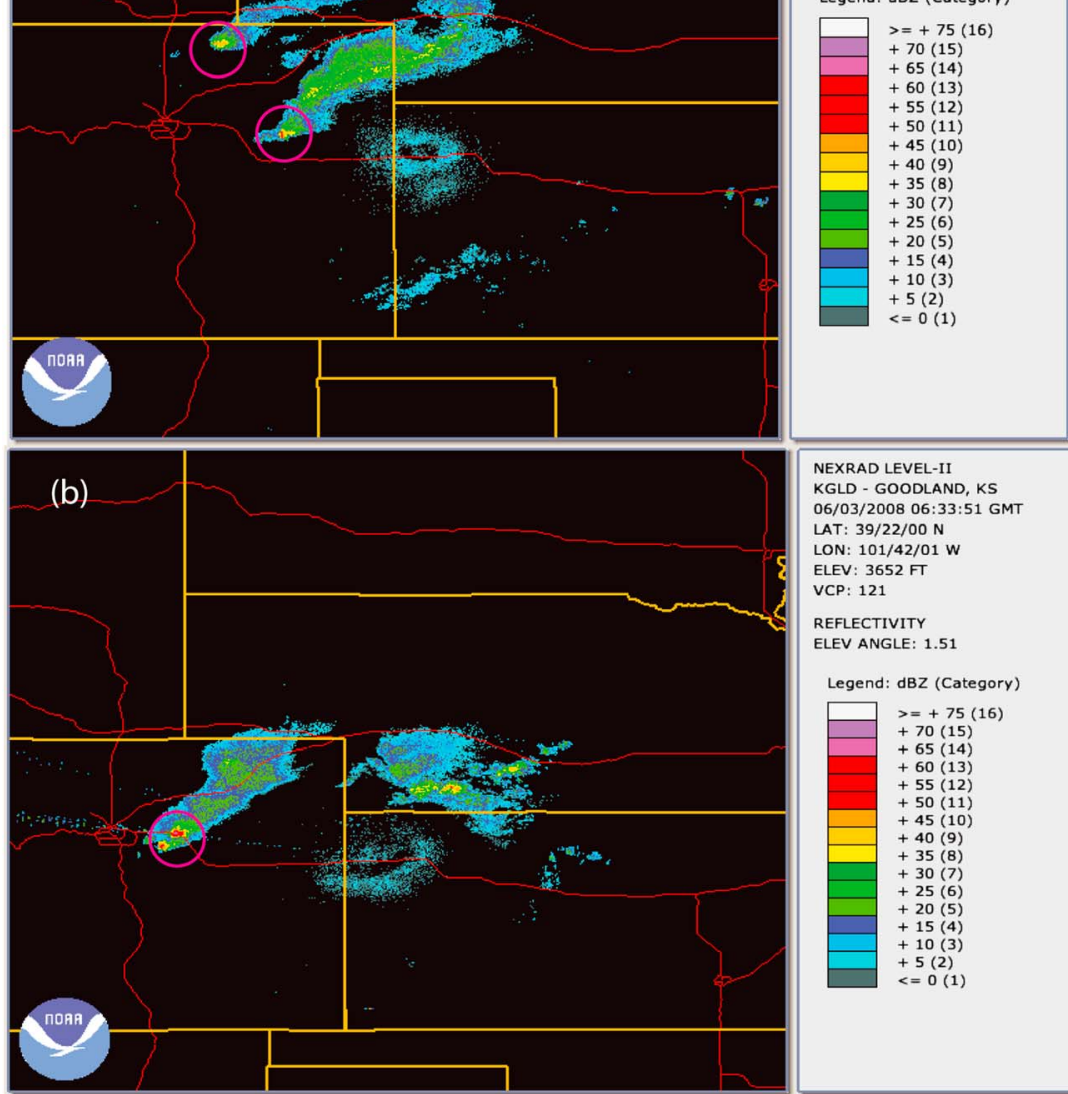

NEXRAD LEVEL-II KGLD GOODLAND, KS 3:51 GMT LAT: $39 / 22 / 00 \mathrm{~N}$ ELEV: 3652 FT VCP: 121

REFLECTIVITY ELEV ANGLE: 1.51

Legend: $\mathrm{dBZ}$ (Category)
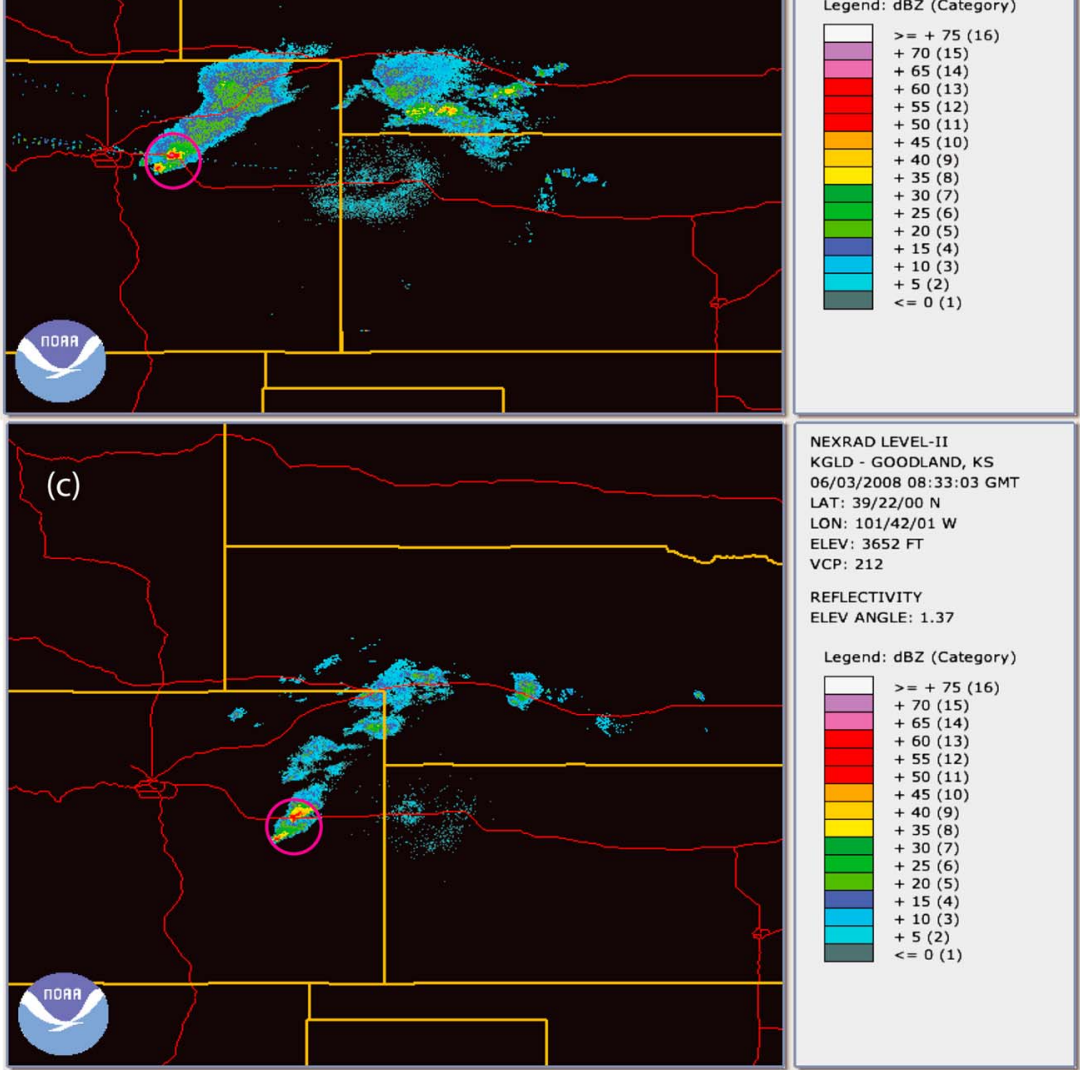

NEXRAD LEVEL-II GOODLAND, KS (4AT: 39/22/08:33:03 GMT LAT: $39 / 22 / 00 \mathrm{~N}$ ELEV: 3652 FT ELEV: 3652

REFLECTIVITY ELEV ANGLE: 1.37 Legend: $\mathrm{dBZ}$ (Category)

\begin{tabular}{l} 
Legend: dBZ (Category) \\
\begin{tabular}{|l}
\hline \\
$>=+75(16)$ \\
\\
$+70(15)$ \\
$+65(14)$ \\
$+60(13)$ \\
$+55(12)$ \\
$+50(11)$ \\
$+45(10)$ \\
$+40(9)$ \\
$+35(8)$ \\
$+30(7)$ \\
$+25(6)$ \\
$+20(5)$ \\
$+15(4)$ \\
$+10(3)$ \\
$+5(2)$ \\
$<=0(1)$ \\
\hline
\end{tabular} \\
\hline
\end{tabular}

Figure 3. NEXRAD reflectivity charts from Goodland, KS on 3 June 2008 at (a) 0428 UT, (b) 0633 UT, and (c) 0833 UT. The color bar shows the radar reflectivity. The yellow and red colors indicate regions of high precipitation rates that are associated with deep convective clouds. These regions are enclosed by red circles.

instability (indicated by $\mathrm{N}^{2}<0$ ). The formation of ripples from convective GW breaking in the mesosphere and lower thermosphere (MLT) is also seen in numerical simulations [Horinouchi et al., 2002].
[17] Clouds gradually moved out of the imager FOV before 0600 UT (Figure 2b). Concentric GWs that emanate northward and eastward can be observed. In addition, northwestward propagating GWs with longer wavelengths 


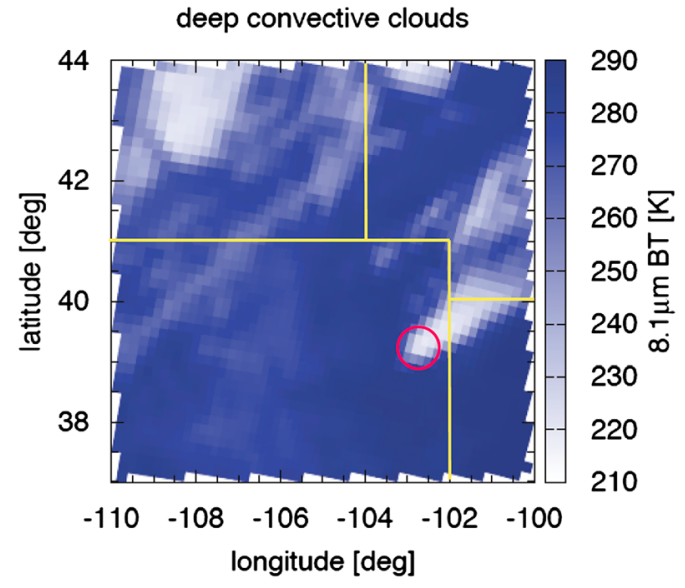

Figure 4. AIRS brightness temperature measurements at $8.1 \mu \mathrm{m}$ on 3 June 2008, $0900 \mathrm{UT}$, indicating cold clouds and deep convection. Yellow lines are state borders as in Figures 1 and 2. The location of tropopause overshooting $(<218 \mathrm{~K})$ is enclosed by a red circle.

$(>100 \mathrm{~km})$ and weaker amplitudes are overlaid on these concentric GWs. Note that the concentric rings in Figure $2 b$ are not as coherent as those at later times (Figures $2 \mathrm{c}$ and $2 \mathrm{~d})$. This is due to the interference from other gravity waves propagating in nearly orthogonal directions that "cut" the concentric rings into pieces in the $\mathrm{OH}$ airglow images. Ripples can also be found near the center of the FOV (denoted by the green arrow in Figure 2b).

[18] At 0800 UT (Figure 2c), the concentric GW patterns become most clear in the southeastern portion of the FOV. Their horizontal wavelengths range from $44 \pm 4 \mathrm{~km}$ in the inner ring to $60 \pm 4 \mathrm{~km}$ in the outer ring; their periods increase from $10 \pm 2 \mathrm{~min}$ northward and $12 \pm 2 \mathrm{~min}$ southward in the inner ring to $14 \pm 2 \mathrm{~min}$ in the outer ring. The increasing periods and horizontal wavelengths as a function of radii (the distance from the wavefront to the apparent center of rings) observed at $0800 \mathrm{UT}$ is in good agreement with the GW dispersion relation, which was illustrated graphically by Figure 5 of Yue et al. [2009]. There are circular wave patterns at the right-hand edge of Figure 2c as well. These waves apparently have different centers from the elliptical GWs to the west; hence they were likely excited by different overshooting plumes. In Figure 2c, we can also see concentric GWs in the Northeast and Southeast (denoted by yellow arrows). Finally, at 0910 UT (Figure 2d), clouds blocked the western half of the FOV. The outer circular rings in the east have horizontal wavelengths of $44 \pm 4 \mathrm{~km}$ and periods of $14 \pm 2 \mathrm{~min}$. The amplitude of the GWs is $\sim 6 \%$ in $\mathrm{OH}$ airglow emission perturbations.

\subsection{NEXRAD Observations of Precipitation}

[19] The NEXRAD maps on 3 June 2008 are used to search for convective plumes and clusters, which could possibly excite concentric GWs. Figure 3 displays the NEXRAD radar maps around $0430 \mathrm{UT}, 0630 \mathrm{UT}$, and 0830 UT, respectively. Around 0430 UT (Figure 3a), two high plumes (denoted by red circles) are seen at the overshooting tops of two squall lines. The anvils extend to the east of the overshooting tops. The northern squall line is closer to the YRFS and is associated with the clouds interfering with the imager observation in the early evening. These two high clouds likely excited the concentric GWs in Figure 2a around 0430 UT. Without simultaneous background wind measurement and careful ray tracing modeling [e.g., Vadas et al., 2012], we cannot determine more exactly when and where the concentric gravity waves were launched. From a larger NEXRAD reflectivity map (Figure 4 in Yue et al. [2009]), it can be seen that a large-size thunderstorm system in eastern Kansas could have excited the northwest propagating large-scale GWs found in Figure 2b. Figure $3 \mathrm{~b}$ shows that the northern squall line diminished before 0630 UT while the southern one (a)

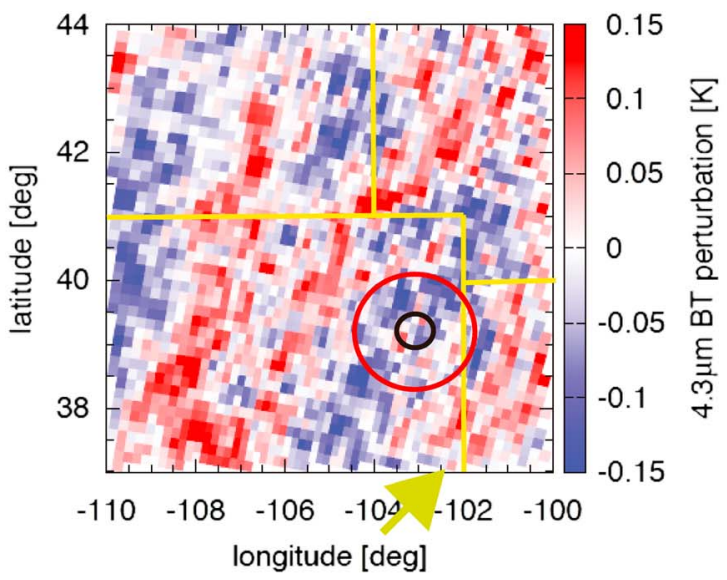

(b)

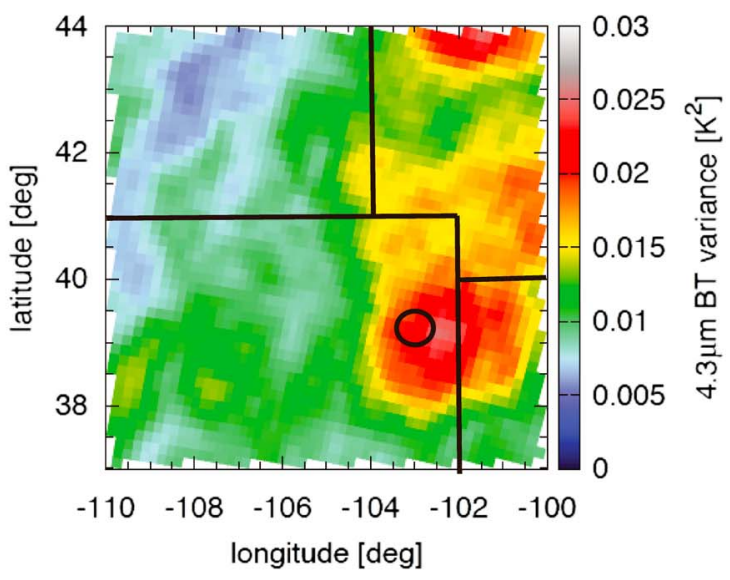

Figure 5. (a) AIRS brightness temperature perturbations at $4.3 \mu \mathrm{m}$ indicating gravity wave activity at 0900 UT on 3 June 2008. The green arrow denotes the circular wave patterns also seen by the $\mathrm{OH}$ imager. (b) Local variance of $4.3 \mu \mathrm{m}$ brightness temperature perturbations. The black circle marks the location of the overshooting plume from Figure 4. The red circle denotes a range of $70 \mathrm{~km}$ from the black circle. 
(a)

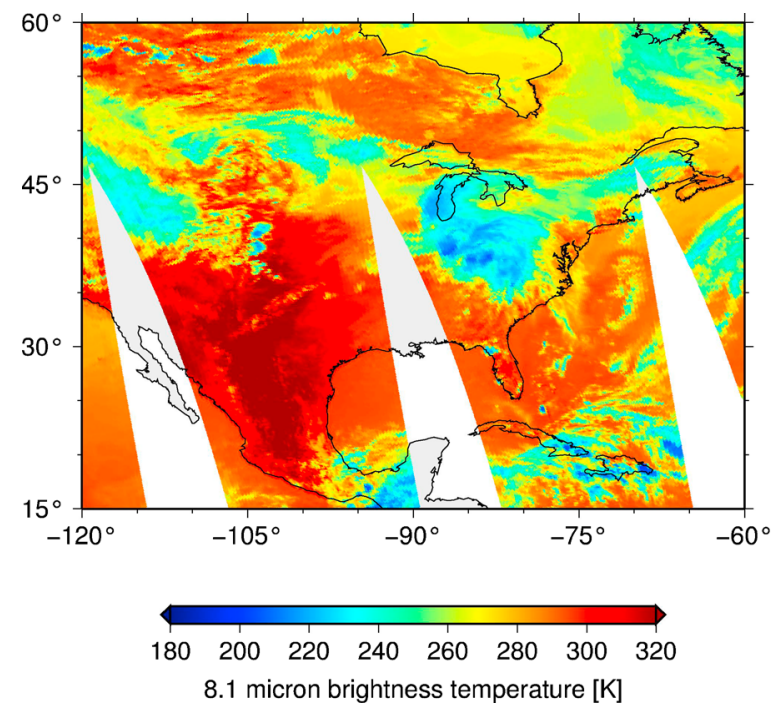

(b)

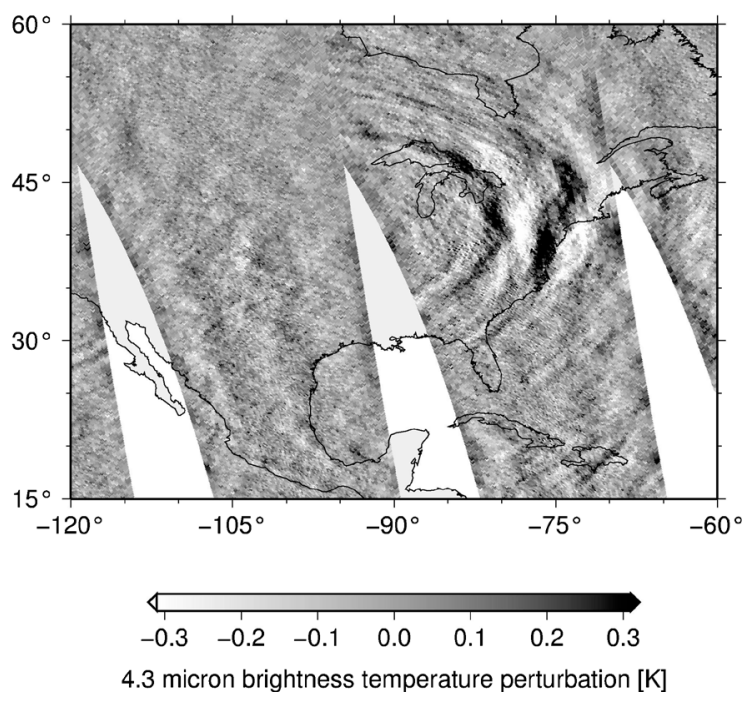

Figure 6. AIRS observations of brightness temperature at (a) $8.1 \mu \mathrm{m}$ and (b) at $4.3 \mu \mathrm{m}$ over North America between 1830 and 2000 UT on 3 June 2008.

continued producing overshooting cloudtops. Two adjacent high plumes can be seen near the overshooting top of the southern squall line (inside the red circle). Recall that in Figure 2c, the elliptical rings near the center and the circular wave patterns near the eastern edge of the FOV have different apparent centers. The two overshooting plumes in Figure $3 b$ could be the convective sources for those two groups of convective GWs seen in Figure 2c. Comparing Figure 3b (at $\sim 0630$ UT) and Figure $3 \mathrm{c}$ (at $\sim 0830$ UT), the high clouds travelled southeastward at a speed of $\sim 50 \mathrm{~km} / \mathrm{h}$. The squall line became weak and stopped producing overshooting tops and high clouds after 0900 UT.

\subsection{AIRS Observations of Deep Convection and Stratospheric Gravity Waves}

[20] On 3 June 2008 at 0 UT, using radiosonde data from several stations on the western Great Plains, the tropopause is measured at about $13 \mathrm{~km}$ with a temperature of $218 \mathrm{~K}$. Figure 4 displays AIRS radiances at $8.1 \mu \mathrm{m}$ for $0900 \mathrm{UT}$. We can see that the location of the overshooting plume with temperatures colder than $218 \mathrm{~K}$ (enclosed by the red circle) is near the high plumes found in Figure 3c. The shape of the squall line is also similar between Figures $3 \mathrm{c}$ and 4. Because AIRS observations do not have as high spatial resolution as the NEXRAD radar, the two overshooting plumes in Figure $3 \mathrm{c}$ are not distinguishable in Figure 4. The AIRS $8.1 \mu \mathrm{m}$ radiances also indicate cold clouds in the north. However, because these clouds have temperatures higher than $220 \mathrm{~K}$, deep convection did not occur and convective GWs were not observed.

[21] Figure 5a shows $\mathrm{CO}_{2}$ brightness temperature perturbations at $4.3 \mu \mathrm{m}$ from AIRS observations on 3 June 2008 at 0900 UT. Semicircular GW patterns with mean perturbations of $0.16 \mathrm{~K}$ emanating southeastward are seen in the lower right corner (denoted by the green arrow). These GWs resemble the circular shape of GWs that were observed in the YRFS airglow images at the same geographical location, $37^{\circ} \mathrm{N}-40^{\circ} \mathrm{N}$ and $100^{\circ} \mathrm{W}-104^{\circ} \mathrm{W}$
(Figure 2d). Despite the comparatively coarse resolution of the AIRS data $(\sim 14 \mathrm{~km} \times 18 \mathrm{~km}$ in the nadir $)$, the horizontal wavelengths of these GWs are estimated to be $60-80 \mathrm{~km}$. Wave periods or velocities cannot be determined by AIRS. Using the period of the GWs (14 $\pm 2 \mathrm{~min})$ measured by the airglow imager at 0910 UT and the Thermosphere-Ionosphere-Mesosphere-Electrodynamics General Circulation Model (TIME-GCM) climatological background zonal wind of $-20 \mathrm{~m} / \mathrm{s}$ at $35 \mathrm{~km}$ in June [Yue et al., 2009, Figure $7 \mathrm{a}]$, the vertical wavelength of the eastward propagating GW is estimated as $35-55 \mathrm{~km}$ based on equation (1). We take an average vertical wavelength of $45 \mathrm{~km}$ and a horizontal wavelength of $70 \mathrm{~km}$ for later calculations. We can confidently say that the vertical wavelengths must be greater than 15-20 km because of the lower detection threshold of AIRS [Hoffmann and Alexander, 2010]. Note that AIRS observed both the concentric GWs and the deep convective cloud top in Figure 5 simultaneously. Because it takes minutes for GWs with long vertical and short horizontal wavelengths to travel upward from their convective sources near the tropopause $(\sim 13 \mathrm{~km})$ to $\sim 35 \mathrm{~km}$ altitude, these GWs were actually excited by a high plume earlier than 9 UT within the same thunderstorm system. In addition to the semicircular GWs near the border between Colorado and Kansas, we can see large-scale GWs having horizontal wavelengths greater than $200 \mathrm{~km}$, which are aligned southwest to northeast in Figure 5a (red and blue bands). Although measured at a different time, these GWs are similar to those northwestward propagating large-scale GWs seen in Figure 2b. Small-scale GWs seen in the airglow imager are likely missed by AIRS, because their horizontal $(<50 \mathrm{~km})$ and vertical wavelengths $(<20 \mathrm{~km})$ are shorter than AIRS's measurable limits (see Table 1).

[22] Figure 5b shows local variances of the detrended 4.3 $\mu \mathrm{m}$ brightness temperature perturbations given in Figure 5a. The local variance covers a circle with $100 \mathrm{~km}$ radius around each footprint. The maximum variance is $0.026 \mathrm{~K}^{2}$ west of the overshooting plume whose location 
is marked by a circle in Figures 4 and 5 . In this case, the local variance exceeds the instrument noise (about $0.001 \mathrm{~K}^{2}$ ) by more than 5 standard deviations, i.e., the event is most certainly caused by GW perturbations. Another area of high GW variances can be found in the northeast corner. These GWs are also observed by the airglow imager (Figure 2c, denoted by yellow arrows) and were likely excited by thunderstorm systems in Nebraska. In the AIRS perturbation map and the variance map, we can identify the GWs from the same convective sources observed with the airglow imager: (i) the concentric GWs in Colorado and Nebraska and (ii) the large-scale GWs travelling northwestward.

[23] The airglow imager cannot observe during daytime due to strong sunlight; on the other hand, AIRS takes measurements at both day and night. The Aqua satellite passes the Great Plains along its ascending orbits around 1830 and 2000 UT in the local afternoon. Figure 6 shows the AIRS measurements of convection (Figure 6a) and GW perturbations (Figure 6b) during the daytime over North America. On the south side of the Great Lakes, a large convective system is observed (Figure 6a), consisting of multiple cold cloud patches (deep blue area). To the east of this convective system, half circles of GW patterns emanating from these convective sources are quite eyecatching in the $4.3 \mu \mathrm{m}$ brightness temperature perturbations (Figure 6b). These GWs have brightness temperature perturbations of $\pm 0.3 \mathrm{~K}$ and horizontal wavelengths of $\sim 500 \mathrm{~km}$. The concentric GWs cover almost the entire east coast of United States. Large-scale GWs like these are difficult to observe using single ground-based all-sky imagers, unless a chain of cameras is carefully deployed.

\section{Discussions}

[24] Gravity waves are quite dispersive in the atmosphere. As illustrated in Figure 1, when GWs propagate from the convective source into higher altitudes, they spread to a larger area on the horizontal plane. GWs with different periods have different propagation zenith angles and radii. The observed concentric GWs occupy the entire FOV of the airglow imager $(800 \mathrm{~km} \times 800 \mathrm{~km})$ in Figure 2, while large GW variances are only adjacent to their convective sources in AIRS $(300 \mathrm{~km} \times 300 \mathrm{~km}$ in Figure 5). The radii of the areas covered with GWs are approximately consistent with the vertical spacing of the height levels where the observations took place $(400 \mathrm{~km} / 87 \mathrm{~km} \approx 150 \mathrm{~km} / 35 \mathrm{~km})$

[25] To estimate the propagation time of the GWs propagating from the stratosphere to the upper mesosphere, we first calculate the vertical group velocity $c_{g z}$ using [Fritts and Alexander, 2003]

$$
c_{g z}=-\frac{N k_{h} m}{\left(k_{h}^{2}+m^{2}+\frac{1}{4 H^{2}}\right)^{3 / 2}}
$$

$c_{g z}$ is estimated as $44 \mathrm{~m} / \mathrm{s}$, given $\lambda_{h}=2 \pi / k_{h}$ is $70 \mathrm{~km}$ and $\lambda_{z}=2 \pi / m$ is $45 \mathrm{~km}$, assuming a constant $-20 \mathrm{~m} / \mathrm{s}$ zonal wind and the Brunt-Vaisala period $2 \pi / \mathrm{N}$ is $5 \mathrm{~min}$. Thus, to propagate from $\sim 35 \mathrm{~km}$ where the AIRS GW measurements take place to the $\mathrm{OH}$ airglow layer $(\sim 87 \mathrm{~km})$, it takes about $20 \mathrm{~min}$. (Detailed calculation of the vertical group velocity with more realistic temperature and wind profiles is made with a ray tracing model in the appendix) The GWs seen in the AIRS observations at 0900 UT therefore should show up in the airglow images around 0920 UT. However, after 0910 UT, clouds moved into the FOV of the YRFS imager, blocking the view of GWs. The GWs observed by the $\mathrm{OH}$ airglow imager at 0910 UT are unlikely the same GWs seen by AIRS although likely being excited by the same convective plume.

[26] Next, we would like to compare the brightness temperature perturbations measured by AIRS with the airglow emission perturbations at $\sim 87 \mathrm{~km}$. Concerning the analysis of the AIRS data, it needs to be taken into account that the observed brightness temperature perturbations do not directly correspond to atmospheric temperature perturbations. Depending on the vertical wavelength of the observed GWs, the observed brightness temperature perturbations are typically much smaller than the stratospheric temperature perturbations. The strength of this damping effect can be assessed by means of radiative transfer calculations. For this assessment we carried out radiative transfer calculations for the AIRS $4.3 \mu \mathrm{m}$ channels for various synthetic temperature profiles $T(z)$, which are composed of a midlatitude background profile $T_{\mathrm{bg}}(z)$ and wave temperature perturbations based on the linear wave theory,

$$
T(z)=T_{\mathrm{bg}}(z)+T_{0} \exp \left(\frac{z-z_{0}}{2 H}\right) \sin \left(2 \pi z / \lambda_{z}+\varphi\right)
$$

[27] First, we calculated the AIRS $4.3 \mu \mathrm{m}$ brightness temperature for different wave amplitudes $T_{0}$ (referring to a reference altitude $z_{0}=35 \mathrm{~km}$ ), vertical wavelengths $\lambda_{z}$, and phases $\varphi$. Second, we determined the maximum perturbation for each amplitude and vertical wavelength by varying the phase. Third, the maximum perturbations are scaled by $1 / \sqrt{2}$ to make them comparable to brightness temperature variance or the AIRS noise signal. Based on these radiative transfer calculations, Figure 7 shows the brightness temperature perturbations for various $\mathrm{GW}$ vertical wavelengths and amplitudes. In Figure 5a, the brightness temperature perturbation for the circular wave fronts is about $0.16 \mathrm{~K}$. We assume that the semicircular GWs were observed at $z_{0} \sim 35 \mathrm{~km}$ by AIRS, as given by the peak height of the temperature weighting function of the analyzed AIRS channels [Hoffmann and Alexander, 2010]. From Figure 7, we concluded that an observed brightness temperature perturbation of $0.16 \mathrm{~K}$ corresponds to wave amplitude of about $0.35 \mathrm{~K}$ at $35 \mathrm{~km}$ altitude for a given vertical wavelength of $45 \mathrm{~km}$.

[28] To compare the temperature perturbation amplitude from AIRS with the $\mathrm{OH}$ imager observation, we have to consider that the temperature amplitude $T^{\prime}(z)$ of linear and unsaturated GWs grows exponentially with height $z$ from the stratosphere to the MLT [e.g., Fritts and Alexander, 2003],

$$
T^{\prime}(z)=T_{0}{ }^{\prime} \exp \left(\frac{z-z_{0}}{2 H}\right)
$$

where $T_{0}{ }^{\prime}$ is the initial GW amplitude at a reference altitude $z_{0}$. Because neither the ripples nor turbulence are found in the late evening, the assumption that the GWs in the airglow imager after 9 UT did not break or were not saturated is 
YUE ET AL.: CONVECTIVELY EXCITED GRAVITY WAVES

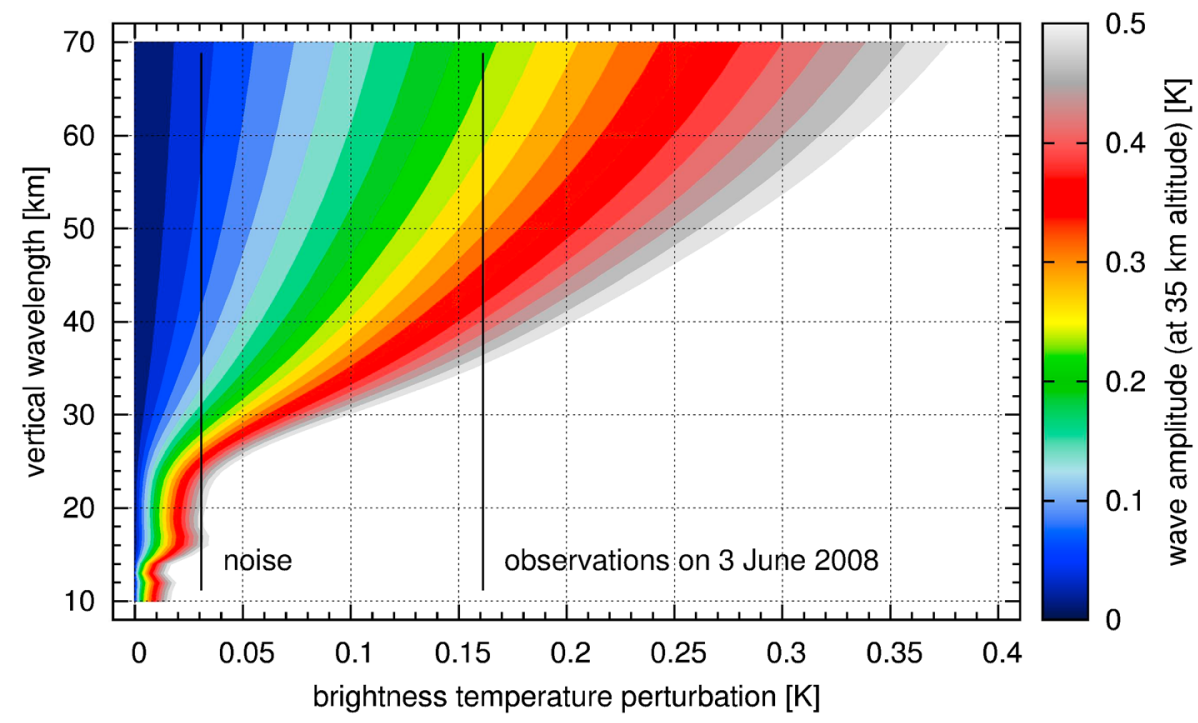

Figure 7. Maximum brightness temperature perturbations scaled by $1 / \sqrt{2}$ for different GW vertical wavelengths and amplitudes at $35 \mathrm{~km}$ based on radiative transfer calculations for the AIRS $4.3 \mu \mathrm{m}$ radiance channels. Black lines indicate the level of observed perturbations for the 3 June 2008 event (right line) and instrument noise (left line), respectively.

reasonable. Using equation (4) and $0.35 \mathrm{~K}$ of wave amplitude at $35 \mathrm{~km}$, the amplitude of the GW perturbation at the $\mathrm{OH}$ layer $\sim 87 \mathrm{~km}$ can be as large as $14 \mathrm{~K}$.

[29] Using the lidar climatological zonal wind of $\sim 30 \mathrm{~m} / \mathrm{s}$ at $87 \mathrm{~km}$ over Colorado in June [Yuan et al., 2008, Figure 3], the vertical wavelength of the eastward propagating GW (with horizontal wavelengths of $60-80 \mathrm{~km}$ and period of $14 \pm 2 \mathrm{~min}$ ) is estimated as $12-20 \mathrm{~km}$ based on equation (1). Similar to the damping factor between the AIRS brightness temperature and GW amplitude, the cancellation factor (CF) is defined as the ratio between the GW airglow intensity perturbation $I^{\prime} / \bar{I}$ and the temperature perturbation $T^{\prime} / \bar{T}[$ Liu and Swenson, 2003; Vadas et al., 2012],

$$
C F=\frac{\max \left(I^{\prime} / \bar{I}\right)}{\max \left(T^{\prime} / \bar{T}\right)}
$$

[30] According to Figure 4 of Vadas et al. [2012], the $\mathrm{CF}$ is $0.5-2$ for the GWs with vertical wavelengths $12-20 \mathrm{~km}$. In June, the average temperature $\bar{T}$ at $87 \mathrm{~km}$ in Colorado is $\sim 160 \mathrm{~K}$ measured by the sodium lidar [Yuan et al., 2008]. Using equation (5), the estimated airglow intensity perturbation $I^{\prime} / \bar{I}$ from a temperature perturbation of $14 \mathrm{~K}$ is about $4 \%-17 \%$. This is on the same order as the emission perturbations measured by the $\mathrm{OH}$ imager $(6 \%)$ in Figure 1e, even though they are likely caused by different GWs.

[31] It is well known that convective sources excite a broad spectrum of GWs that have a large range of wavelengths, periods, and amplitudes [e.g., Holton and Alexander, 1999; Lane et al., 2001; Song et al., 2003; Alexander and Barnet, 2007; Vadas et al., 2009]. Note that the circular GWs observed in the MLT by the airglow imager at 0910 UT (Figure 2d) have horizontal wavelengths of about $44 \mathrm{~km}$, whereas the semicircular GWs seen in AIRS at 0900 UT (Figure 5a) have wavelengths of
60-80 km. We likely see different GWs excited by the same convective plume in AIRS and the $\mathrm{OH}$ images. The GWs reaching the airglow layer at 0910 UT should have faster vertical group velocity than those seen in AIRS at $0900 \mathrm{UT}$, which is expected to arrive at the airglow layer at $\sim 0920 \mathrm{UT}$.

[32] A 2-D ray-tracing calculation is performed in Appendix A to simulate the $\mathrm{GW}$ propagations from the convective source through the stratosphere into the MLT. The numerical simulations are qualitatively consistent with the AIRS and airglow imager observations.

\section{Summary and Outlook}

[33] In this paper, we report, for the first time, simultaneous observations of convective GWs using the spaceborne AIRS experiment and a ground-based airglow imager. Measurements were made over the North American Great Plains on 3 June 2008. NEXRAD data and AIRS observations show that these GWs were excited by multiple deep convective plumes in two convective systems. Although the AIRS $8.1 \mu \mathrm{m}$ radiances provide a coarse resolution for detecting convective systems and high clouds, it can serve as a good proxy of the NEXRAD data to search for convective GW sources. In particular, in the regions where the NEXRAD or other Doppler weather radars are not deployed (for example, over the ocean), the AIRS $8.1 \mu \mathrm{m}$ radiances are very useful to identify convective sources for GWs for climatological studies.

[34] The centers of the concentric-shaped GWs coincide with the high convective plumes. Similar circular wave shapes are seen in both airglow images and AIRS data around 0900 UT (at the time of the satellite overpass). The GWs observed by AIRS have horizontal wavelengths of $60-80 \mathrm{~km}$. Although the brightness temperature perturbations observed by AIRS are small, a map of local variances with maxima of $0.026 \mathrm{~K}^{2}$ confirms that significant 
GW activity took place in eastern Colorado and northwestern Nebraska. Small-scale GWs with horizontal wavelengths shorter than $50 \mathrm{~km}$ are only observed in the airglow imager. Large-scale GWs with wavelengths $>100 \mathrm{~km}$ emanating northwestward are seen clearly in both instruments. Because ripples associated with breaking GWs are only observed in the early evening, we assume that the concentric GWs in the MLT at $\sim 9$ UT (3 LT) are unsaturated and stable. The amplitude of the GWs grows exponentially with height from the stratosphere to the MLT and can have $14 \mathrm{~K}$ in temperature perturbations around $87 \mathrm{~km}$ based on AIRS data. Thus, taking into account the cancellation factor of the airglow imager, we estimate the airglow intensity perturbation to be $4 \%-17 \%$. This is on the same scale of $6 \%$ measured by the $\mathrm{OH}$ imager for a different GW.

[35] Joint GW observations by AIRS and ground-based airglow imagers provide a new way to investigate the propagation and evolution of GWs between the stratosphere and mesosphere and how the background atmosphere affects this process. The combination of two observational methods covers a much broader spectrum of GWs, from small-scale (kilometers) to large-scale (thousands of kilometers) waves, with simultaneous local and global coverage and temporal resolution. The $\mathrm{OH}$ imager sees more small-scale GWs in Figure 2 while AIRS observes very large GWs over the east US in Figure 6. With GWs being observed independently at two separate altitude regions of the atmosphere, the better understanding of the changes of the GW spectrum can help to validate the GW parameterizations used in general circulation models [Alexander and Barnet, 2007; Alexander et al., 2010]. With GW events seen in AIRS but not in the airglow imager, we can speculate that GWs are possibly either filtered or break from the stratosphere to the mesosphere. With simultaneous temperature and wind information obtained from radiosondes, satellites, lidars, and radars, and ray tracing or mesoscale numerical models [e.g., Vadas et al., 2012], we can comprehensively reveal the process how GWs reach the upper atmosphere.

[36] With strong convection around, airglow imager observations are often blocked by cloudy weather. On the other hand, the joint observation of convective GW activity is a challenge for AIRS because of the small wave amplitudes involved. A clear wave signal in the $\mathrm{OH}$ imager (e.g., $5 \mathrm{~K}$ amplitude, or 10\% airglow emission perturbation for $\mathrm{GW} \lambda_{z}=20 \mathrm{~km}$ ) corresponds only to a weak signal in AIRS $(0.12 \mathrm{~K}$ amplitude, or $0.04 \mathrm{~K}$ brightness temperature perturbation for $\lambda_{z}=40 \mathrm{~km}$, just above the noise level). Therefore, simultaneous observations of GWs in both instruments are rarely found in our database. Future satellite experiments with better precision and signal to noise ratio could improve the detection of convective GWs and increase the chances of joint observations with ground-based airglow imagers.

[37] Along with circular wave patterns in the satellite radiances and airglow emissions caused by convective GWs, similar concentric patterns can also be found in the total electron content disturbances in the ionosphere after GWs are triggered by a point source like thunderstorms or a severe earthquake [Tsugawa et al., 2011]. In future work, we will correlate the concentric GW patterns in satellite data, airglow images, and total electron content, extending the joint observations from the stratosphere to the thermosphere and ionosphere.

\section{Appendix A: 2-D Ray Tracing of the Convective GWs}

[38] We use a linear ray trace model to simulate the propagation of the GWs observed by the airglow imager and AIRS through realistic background wind and stability fields. Detailed description and applications of this model can be found in Alexander [1996, 1998] and Alexander and Rosenlof [1996]. The amplitude of the GW is constrained by conservation of wave action flux unless its amplitude is unstable [Alexander, 1998]. The dispersion relation includes the effects of rotation at low frequencies and nonhydrostatic effects at higher frequencies. Total internal reflection occurs when the high-frequency GW is cutoff [Marks and Eckermann, 1995].

[39] Reanalysis and model or reference data are combined to form realistic background fields in the stratosphere and mesosphere for the ray tracing simulations. Figure A1 displays the resembled input profiles for pressure, temperature and corresponding buoyancy frequency taken from CIRA-86 data (above $\sim 50 \mathrm{~km}$ ) (The COSPAR International Reference Atmosphere) [CIRA, 1986a, 1986b] and averaged ERA-Interim data [Uppala et al., 2005; Dee et al., 2011] (below $\sim 50 \mathrm{~km}$ ) for 3 June 2008 at 6 and 12 UT. The CIRA zonal wind has a strong westward jet of $-60 \mathrm{~m} / \mathrm{s}$ at $70 \mathrm{~km}$. This causes internal reflection of a few GWs and blocks them from penetration into the MLT. This CIRA-86 wind profile is about $20 \mathrm{~m} / \mathrm{s}$ greater than that of ERA-Interim and climatological output in June from the TIME-GCM [Yue et al., 2009]. The tidal wind amplitudes can be as large as $20 \mathrm{~m} / \mathrm{s}$ at $70 \mathrm{~km}$ [Forbes, 1995], which is not included in CIRA. Considering the uncertainties from the CIRA profiles, the ERA-Interim zonal wind below $50 \mathrm{~km}$ is instead merged with the TIME-GCM zonal wind above $50 \mathrm{~km}$, as shown in Figure A1c.

[40] Five monochromatic eastward propagating GWs are individually launched above the troposphere at $18 \mathrm{~km}$, where the zonal wind is nearly 0 (see Figure A1c). Vertical wavelengths of these GWs are about $18 \mathrm{~km}$ at the launch level, which is about the depth of the convective heating [Holton et al., 2002]. On the other hand, the frequencies and horizontal wavelengths have broader spectra. Two monochromatic GWs are selected to represent the GWs observed in the $\mathrm{OH}$ imager. Both have periods of $14 \mathrm{~min}$. One has a horizontal wavelength of $44 \mathrm{~km}$, corresponding to the GWs observed at 0910 UT (Figure 2d). The other wave has a wavelength of $60 \mathrm{~km}$, corresponding to the GWs in the outer rings at 0800 UT (Figured 2c). Three monochromatic GWs with horizontal wavelengths of 60,70 , and $80 \mathrm{~km}$ represent those observed by AIRS $\left(\lambda_{z}=60-80 \mathrm{~km}\right)$ at $0900 \mathrm{UT}$ in Figure $5 \mathrm{a}$. Because the periods cannot be determined from the measurements, we select three periods of $15.9,18.4$, and $20.8 \mathrm{~min}$ to yield a vertical wavelength of $\sim 18 \mathrm{~km}$ at the tropopause.

[41] Figure A2 exhibits the evolutions of vertical wavelengths $\lambda_{z}$, intrinsic wave period and vertical group velocities $c_{g z}$ with height. While propagating upward above the tropopause, vertical wavelengths of all GWs 
(a)

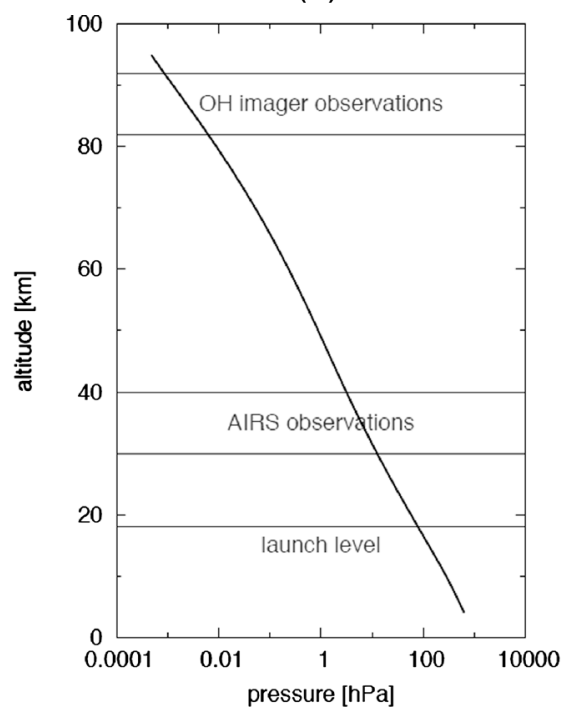

(c)

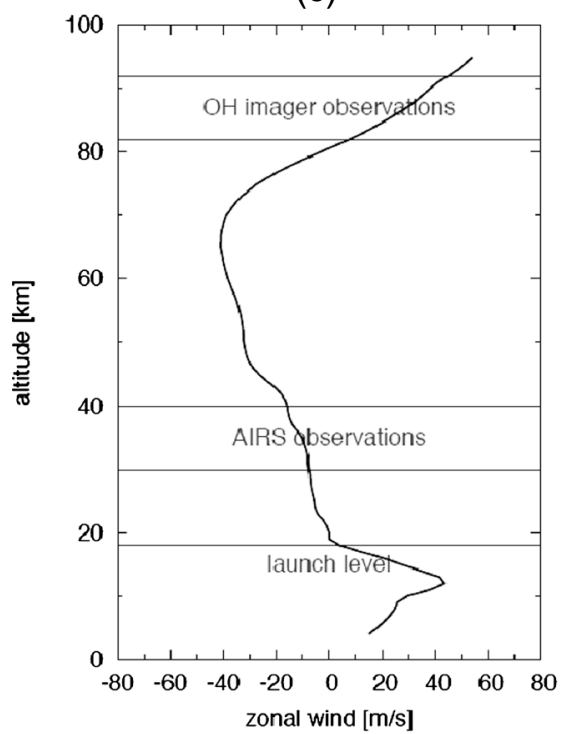

(b)

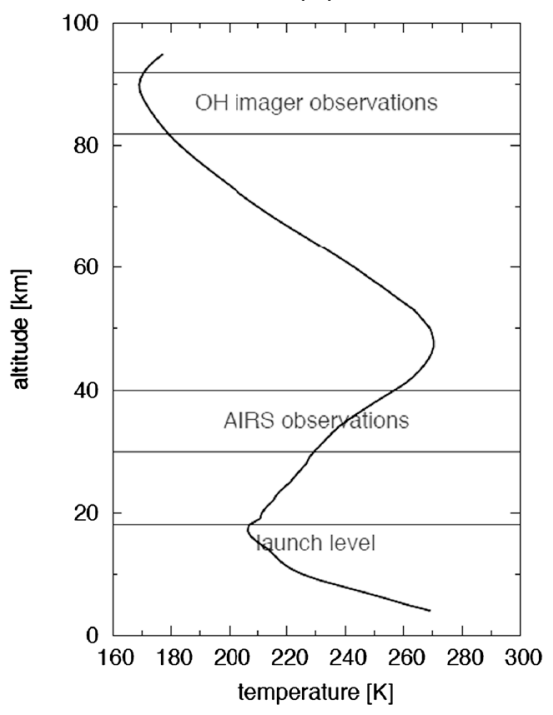

(d)

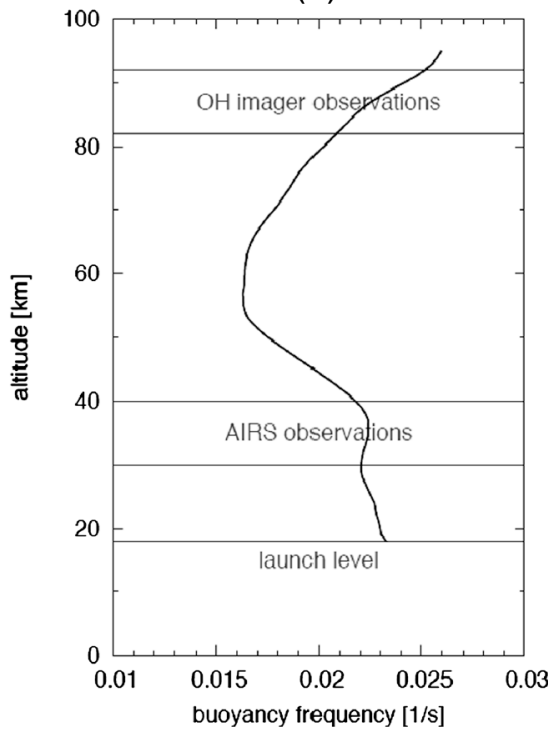

Figure A1. Profiles of (a) pressure (hPa), (b) temperature $(\mathrm{K})$, (c) zonal wind (m/s), and (d) buoyancy frequency $(1 / \mathrm{s})$ between 0 and $100 \mathrm{~km}$ in June 2008. The pressure and temperature profiles are resembled by the CIRA-86 profiles above $50 \mathrm{~km}$ and the average of ERA-Interim profiles (06h and 12h) below $50 \mathrm{~km}$. The zonal wind is composed of ERA-Interim below $50 \mathrm{~km}$ and TIME-GCM above $50 \mathrm{~km}$. A smooth transition is taken at 40-60 km, i.e., 100\% ERA-Interim and 0\% CIRA/TIME-GCM at $40 \mathrm{~km}, 50 \%$ ERAInterim and 50\% CIRA/TIME-GCM at $50 \mathrm{~km}$ and $0 \%$ ERA-Interim and 100\% CIRA/TIME-GCM at $60 \mathrm{~km}$. The black line at $18 \mathrm{~km}$ denotes the GW launch level. Two black lines at 30 and $40 \mathrm{~km}$ enclose the $\mathrm{CO}_{2}$ layer where the AIRS $4.3 \mu \mathrm{m}$ measurement takes place. Two black lines at 82 and $92 \mathrm{~km}$ denote the $\mathrm{OH}$ airglow layer $(87 \pm 5 \mathrm{~km})$.

first increase toward the height of $70 \mathrm{~km}$ and decrease above $70 \mathrm{~km}$. This is consistent with the dispersion relation, equation (1), and the zonal wind profile in Figure A1c. Near the $\mathrm{CO}_{2} 4.3 \mu \mathrm{m}$ emission layer at $30-40 \mathrm{~km}$, the vertical wavelengths for the three AIRS GWs are $\sim 25 \mathrm{~km}$ (blue line in Figure A2a). The vertical wavelengths for the $\mathrm{OH}$ imager observed GWs are $15-25 \mathrm{~km}$ when the waves enter the airglow layer at $82-92 \mathrm{~km}$. According to Table 1, these vertical wavelengths are detectable by AIRS and the $\mathrm{OH}$ imager. The intrinsic wave period is defined as $\tau_{\mathrm{IR}}=2 \pi / \omega_{\mathrm{IR}}$, where $\omega_{\text {IR }}$ is the intrinsic (Doppler-shifted) frequency. For GWs propagating in background wind fields $U_{h}$,

$$
\omega_{\mathrm{IR}}=\omega_{0}-k_{h} U_{h}
$$

where $\omega_{0}$ is the apparent frequency prior selected. From Figure A2b, we can see that the intrinsic periods decease below $70 \mathrm{~km}$ and increase sharply above $70 \mathrm{~km}$, corresponding to the westward jet at $70 \mathrm{~km}$ and eastward wind in the MLT (Figure A1c). From Figure A2c, vertical group velocities 
(a)

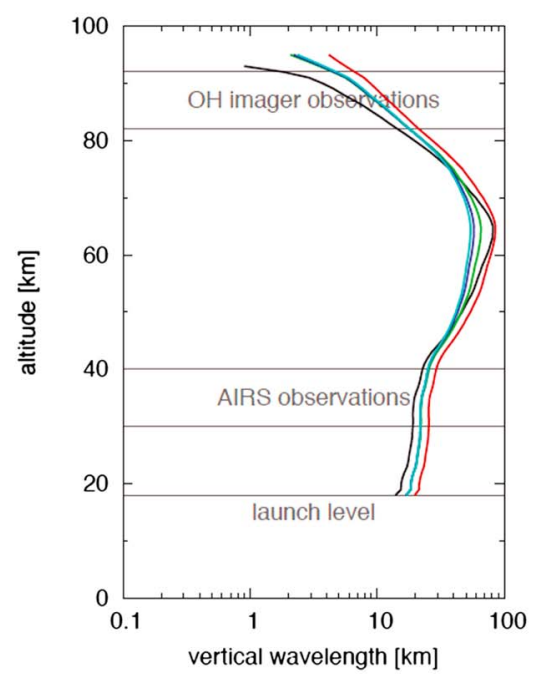

(c)

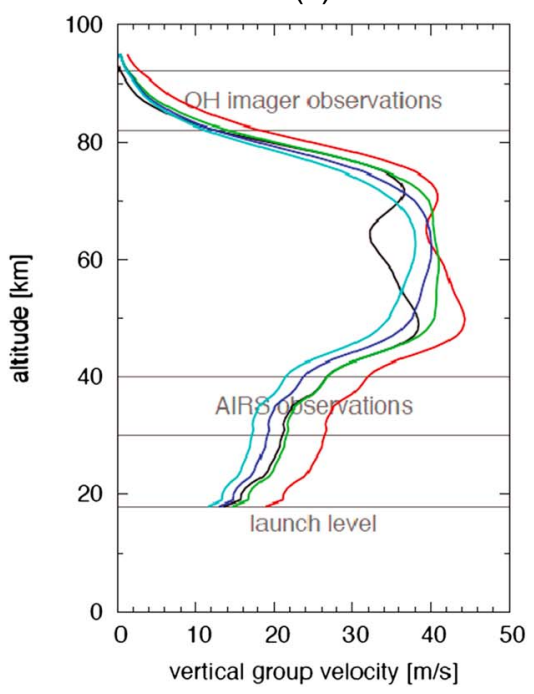

(b)
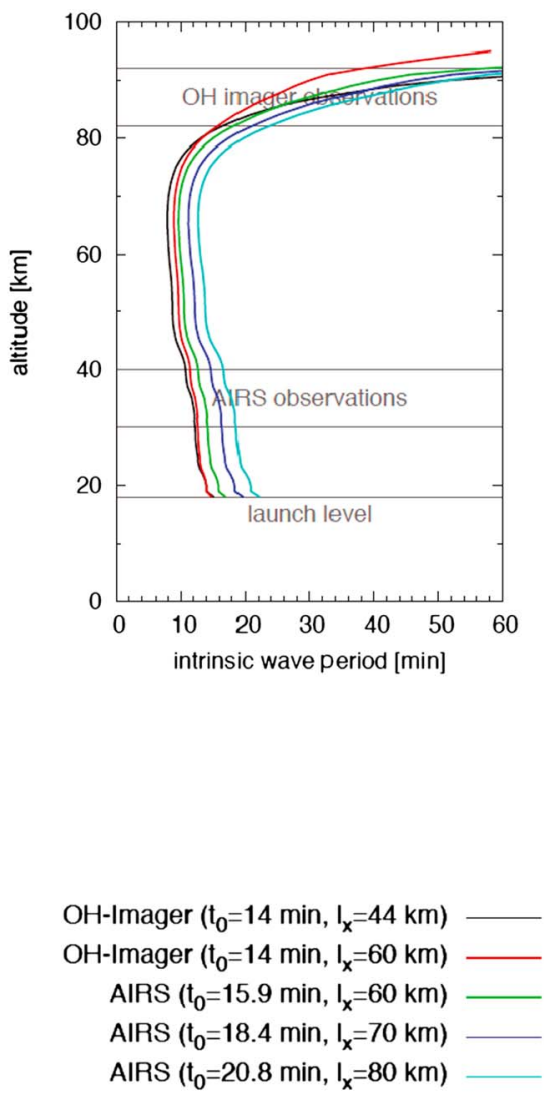

Figure A2. Evolutions of (a) vertical wavelengths, (b) intrinsic wave periods, and (c) vertical group velocities for 5 monochromatic GWs discussed in the appendix. Black, red, green, purple, and blue lines denote the $5 \mathrm{GWs}$, respectively. The black line at $18 \mathrm{~km}$ denotes the GW launch level. Two black lines at 30 and $40 \mathrm{~km}$ enclose the $\mathrm{CO}_{2}$ layer where the AIRS $4.3 \mu \mathrm{m}$ measurement takes place. Two black lines at 82 and $92 \mathrm{~km}$ denote the $\mathrm{OH}$ airglow layer $(87 \pm 5 \mathrm{~km})$.

rise to $30-40 \mathrm{~m} / \mathrm{s}$ near $70 \mathrm{~km}$ and decrease rapidly toward $10 \mathrm{~m} / \mathrm{s}$ at the $\mathrm{OH}$ airglow layer, ending with zero approaching the height of $100 \mathrm{~km}$. Therefore, these GWs cannot propagate beyond the MLT.

[42] The ray trace program allows to estimate the propagation time and horizontal distance from the source are estimated, as shown in Figure A3. In Figure A3a, for the GWs observed by AIRS at 0900 UT (green, purple, and blue lines), the propagation time is around 10-20 min to reach $30-40 \mathrm{~km}$ and $35-45 \mathrm{~min}$ to $82 \mathrm{~km}$. Thus, these GWs are likely excited at $0840-0850$ UT. For the GWs observed by the $\mathrm{OH}$ imager at $0910 \mathrm{UT}$ with $\tau_{0}=14 \mathrm{~min}$ and $\lambda_{h}=44 \mathrm{~km}$ (black line), it takes about $45 \mathrm{~min}$ for the GW from the source to reach the airglow layer. This GW may be excited around 0825 UT. Furthermore, from Figure A3b, GWs observed in AIRS at $0900 \mathrm{UT}$ and at $40 \mathrm{~km}$ altitude (green, purple, and blue lines) are estimated to be $60-80 \mathrm{~km}$ horizontally away from their convective source. In Figure $5 \mathrm{a}$, the curved patterns with horizontal wavelengths of $60-80 \mathrm{~km}$ are about $100-150 \mathrm{~km}$ from the convective source. The ray tracing model underestimates the horizontal propagation of the GWs. The GW seen by the $\mathrm{OH}$ imager (black line in Figure A3b) extends horizontally $70-200 \mathrm{~km}$ from the source in the airglow layer. This is comparable to the airglow observations in Figure $2 \mathrm{~d}$. A portion of the concentric GWs is enclosed in the red circle $(200 \mathrm{~km}$ away from the convective source, denoted by the red dot).

[43] Considering that there exist uncertainties in the wave parameters and the background fields, the observations of the GWs and convection by AIRS and the airglow imager are in general agreement with the linear ray tracing results. These simulations further confirm our speculations that the 


\section{YUE ET AL.: CONVECTIVELY EXCITED GRAVITY WAVES}

(a)

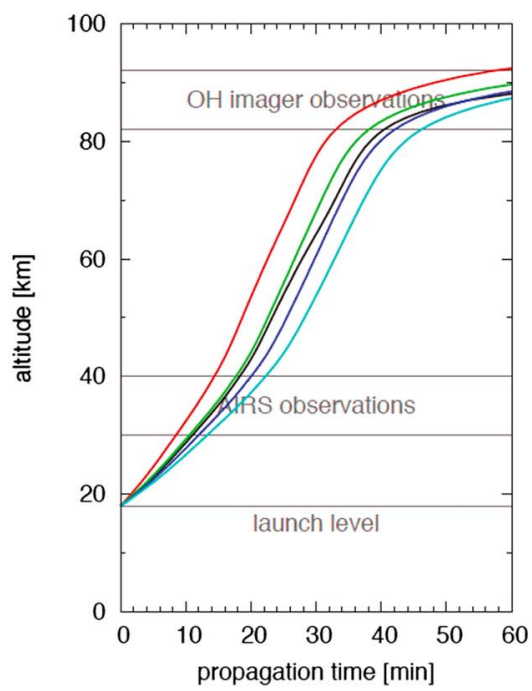

(b)

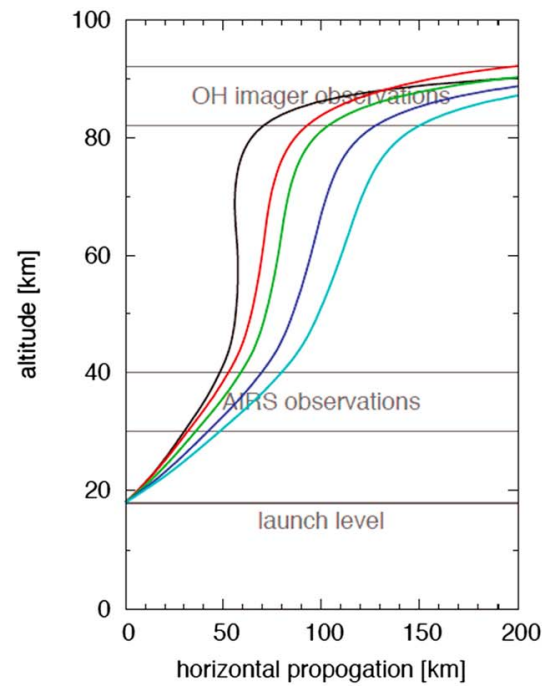

$$
\begin{array}{r}
O H \text {-Imager }\left(t_{0}=14 \mathrm{~min}, \mathrm{I}_{x}=44 \mathrm{~km}\right) \\
\text { OH-Imager }\left(\mathrm{t}_{0}=14 \mathrm{~min}, \mathrm{I}_{\mathrm{x}}=60 \mathrm{~km}\right) \\
\text { AIRS }\left(\mathrm{t}_{0}=15.9 \mathrm{~min}, \mathrm{I}_{x}=60 \mathrm{~km}\right) \\
\text { AIRS }\left(\mathrm{t}_{0}=18.4 \mathrm{~min}, \mathrm{I}_{x}=70 \mathrm{~km}\right) \\
\text { AIRS }\left(\mathrm{t}_{0}=20.8 \mathrm{~min}, \mathrm{I}_{x}=80 \mathrm{~km}\right)
\end{array}
$$

Figure A3. (a) Propagation time and (b) horizontal distance from the source at $18 \mathrm{~km}$ for the five GWs discussed in Appendix A. The definitions of line colors are the same as Figure A2.

GWs seen in AIRS and the airglow imager were excited by the same convective system, although they are from different portions within the broad GW spectrum.

[44] Acknowledgments. AIRS data are distributed by the NASA Goddard Earth Sciences Data Information and Services Center. The NEXRAD data are obtained from http://www.ncdc.noaa.gov/nexradinv/. The radiosonde data are provided by University of Wyoming, Department of Atmospheric Science, http://weather.uwyo.edu/upperair/sounding.html. M. J. A. was supported by The Science of Terra and Aqua NASA contract \#NNH11CD34C. The authors thank Takuji Nakamura for providing the YRFS airglow imager data, which was operated under a support by JSPS grant-in-aids (14403008 and 20403011). The authors are grateful to insightful discussions with Jie Gong.

\section{References}

Alexander, M. J., J. R. Holton, and D. R. Durran (1995), The Gravity Wave Response Above Deep Convection in a Squall Line Simulation, J. Atmos. Sci., 52, 2212-2226.

Alexander, M. J., and K. H. Rosenlof (1996), Nonstationary gravity wave forcing of the stratospheric zonal mean wind, J. Geophys. Res., 101, 23,465-23,474, doi:10.1029/96JD02197.

Alexander, M. J. (1998), Interpretations of observed climatological patterns in stratospheric gravity wave variance, J. Geophys. Res., 103, 8627-8640, doi:10.1029/97JD03325.

Alexander, M. J. (1996), A simulated spectrum of convectively generated gravity waves: Propagation from the tropopause to the mesopause and effects on the middle atmosphere, J. Geophys. Res., 101, 1571-1588, doi:10.1029/95JD02046.

Alexander, M. J., and H. Teitelbaum (2007), Observation and analysis of a large amplitude mountain wave event over the Antarctic peninsula, J. Geophys. Res., 112, D21103, doi:10.1029/2006JD008368.

Alexander, M. J. and C. Barnet (2007), Using satellite observations to constrain parameterizations for global models, J. Atmos. Sci., 64 .

Alexander, M. J., et al. (2010), Recent developments in gravity wave effects in climate models, and the global distribution of gravity wave momentum flux from observations and models, Q. J. Roy. Meteorol. Soc., 136.
Aumann, H. H., D. Gregorich and S. M. DeSouza-Machado (2006), AIRS observations of deep convective clouds, Proc. SPIE, 6301, 63010J, doi:10.1117/12.681201.

Aumann, H. H., et al. (2003), AIRS/AMSU/HSB on the Aqua mission: Design, science objective, data products, and processing systems, IEEE Trans. Geosci. Remote Sens., 41(2), 253-264, doi:10.1109/ TGRS.2002.808356.

CIRA (1986a), Part I Thermospheric Models, Advances in Space Research (ISSN 0273-1177), edited by D. Rees, 8(5-6), 1988, $476 \mathrm{p}$.

CIRA (1986b), Part II Middle Atmosphere Models, Advances in Space Research (COSPAR), edited by D. Rees, J. J. Barnett, K. Labitzke, 10(12), 1990.

Dee, D. P., et al. (2011), The ERA-Interim reanalysis: configuration and performance of the data assimilation system. Q.J. R. Meteorol. Soc. 137, 553-597, doi:10.1002/qj.828.

Dewan, E. M., R. H. Picard, R. R. O'Neil, H. A. Gardiner, J. Gibson, J. D. Mill, E. Richards, M. Kendra, and W. O. Gallery (1998), MSX satellite observations of thunderstorm-generated gravity waves in mid-wave infrared images of the upper stratosphere, Geophys. Res. Lett., 25, 939-942.

Eckerman, S. D., J. Ma, D. L. Wu, D. Broutman (2007), A three dimensional mountain wave imaged in satellite radiance throughout the stratosphere: Evidence of the effects of directional wind shear, $Q . J$. R. Meteorol. Soc., 133 .

Forbes, J. M. (1995), Tidal and Planetary waves, Geophys. Monogr., 87

Fritts, D. C., and M. J. Alexander (2003), Gravity wave dynamics and effects in the middle atmosphere, Rev. Geophys., 41(1), 1003, doi:10.1029/ 2001RG000106.

Gong, J., D. L. Wu, and S. D. Eckermann (2012), Gravity wave variances and propagation derived from AIRS radiances, Atmos. Chem. Phys., 12. Grimsdell, A. W., M. J. Alexander, P. T. May, and L. Hoffmann (2010) Model study of waves generated by convection with direct validation via satellite, J. Atmos. Sci., 5.

Hecht, J. H. (2004), Instability layers and airglow imaging, Rev. Geophys., 42, RG1001, doi:10.1029/2003RG000131.

Hecht, J. H., et al. (2009), Imaging of atmospheric gravity waves in the stratosphere and upper mesosphere using satellite and ground-based observations over Australia during the TWPICE campaign, J. Geophys. Res., 114, D18123, doi:10.1029/2008JD011259. 


\section{YUE ET AL.: CONVECTIVELY EXCITED GRAVITY WAVES}

Hoffmann, L., and M. J. Alexander (2009), Retrieval of stratospheric temperatures from Atmospheric Infrared Sounder radiance measurements for gravity wave studies, J. Geophys. Res., 114, D07105, doi:10.1029/ 2008JD011241.

Hoffmann, L., and M. J. Alexander (2010), Occurrence frequency of convective gravity waves during the North American thunderstorm season, J. Geophys. Res., 115, D20111, doi:10.1029/2010JD014401.

Holton, J. R. (1982), The Role of Gravity Wave Induced Drag and Diffusion in the Momentum Budget of the Mesosphere. J. Atmos. Sci., 39, 791-799.

Holton, J. R., J. H. Beres, X. Zhou (2002), On the Vertical Scale of Gravity Waves Excited by Localized Thermal Forcing. J. Atmos. Sci., 59(12), 2019-2023., doi:http://dx.doi.org/10.1175/1520-0469(2002)059<2019: OTVSOG $>2.0 . \mathrm{CO} ; 2$

Holton, J. R., and M. J. Alexander (1999), Gravity waves in the mesosphere generated by tropospheric convection, Tellus, 51A-B, 45-58.

Horinouchi, T., T. Nakamura, and J.-I. Kosaka (2002), Convectively generated mesoscale gravity waves simulated throughout the middle atmosphere, Geophys. Res. Lett., 29(21), 2007, doi:10.1029/2002GL016069.

Kim, S.-Y., H.-Y. Chun, and D. L. Wu (2009), A study on stratospheric gravity waves generated by Typhoon Ewiniar: Numerical simulations and satellite observations, J. Geophys. Res., 114, D22104, doi:10.1029/ 2009JD011971.

Lane, T. P., M. J. Reeder, and T. L. Clark (2001), Numerical modeling of gravity waves generated by deep tropical convection, J. Atmos. Sci., 58, 1249-1274.

Liu, A. Z., and G. R. Swenson (2003), A modeling study of $\mathrm{O} 2$ and $\mathrm{OH}$ airglow perturbations induced by atmospheric gravity waves, J. Geophys. Res., 108(D4), 4151, doi:10.1029/2002JD002474.

Marks, C. J., and S. D. Eckermann (1995), A Three-Dimensional Nonhydrostatic Ray-Tracing Model for Gravity Waves: Formulation and Preliminary Results for the Middle Atmosphere, J. Atmos. Sci., 52, 1959-1984, doi:http://dx.doi.org/10.1175/1520-0469(1995)052<1959: ATDNRT $>2.0 . \mathrm{CO} ; 2$

Mende, S. B., H. Frey, S. P. Geller, and G. R. Swenson (1998), Gravity wave modulated airglow observation from spacecraft, Geophys. Res. Lett., 25, 757-760, doi:10.1029/97GL03224.

Nakamura, T., T. Fukushima, T. Tsuda, C. Y. She, B. P. Williams, D. Krueger, and W. Lyons (2005), Simultaneous observation of dual-site airglow imagers and a sodium temperature-wind lidar, and effect of atmospheric stability on the airglow structure, Adv. Space Res., 35(11), 1957-1963, doi:10.1016/j.asr.2005.05.102.

Piani, C., D. Durran, M.J. Alexander, and J. R. Holton (2000), A numerical study of three-dimensional gravity waves triggered by deep tropical convection and their role in the dynamics of the QBO, J. Atmos. Sci. 57, 3689-3702.

Richter, J. H., F. Sassi, and R. R. Garcia (2010), Toward a physically based gravity wave source parameterization in a General Circulation
Model, J. Atmos. Sci., 67, 136-156, doi:http://dx.doi.org/10.1175/ 2009JAS3112.1.

Sentman, D. D., E. M. Wescott, R. H. Picard, J. R. Winick, H. C. Stenbaek Nielsen, E. M. Dewan, D. R. Moudry, F. T. Sao Sabbas, M. J. Heavner, and J. Morrill (2003), Simultaneous observations of mesospheric gravity waves and sprites generated by a midwesterm thunderstorm, J. Atmos. Terr. Phys., 65(5), 537-550, doi:10.1016/S1364-6826(02)00328-0.

Song, I.-S., H.-Y. Chun, and P. P. Lane (2003), Generation mechanisms of convectively forced internal gravity waves and their propagation to the stratosphere, J. Atmos. Sci., 60, 1960-1980, doi:http://dx.doi.org/ 10.1175/1520-0469(2003)060<1960:GMOCFI >2.0.CO;2.

Suzuki, S., K. Shiokawa, Y. Otsuka, T. Ogawa, K. Nakamura, and T. Nakamura (2007), A concentric gravity wave structure in the mesospheric airglow images, J. Geophys. Res., 112, D02102, doi:10.1029/ 2005JD006558.

Taylor, M. J., and M. A. Hapgood (1988), Identification of a thunderstorm as a source of short period gravity waves in the upper atmospheric nightglow emissions, Planet. Space Sci., 36, 975-985, doi:10.1016/0032-0633 (88)90035-9.

Tsugawa, T., A. Saito, Y. Otsuka, M. Nishioka, T. Maruyama, H. Kato, T. Nagatsuma, and K. T. Murata (2011), Ionospheric disturbances detected by GPS total electron content observation after the 2011 off the Pacific coast of Tohoku Earthquake, Earth Planets Space, 63(70), pp. 875-879, doi:10.5047/eps.2011.06.035.

Uppala, S., et al. (2005), The ERA-40 re-analysis, Q. J. R. Meteorol. Soc., 131, 2961-3012, doi:10.1256/qj.04.176.

Vadas, S. L., J. Yue, C.-Y. She, P. Stamus, and A. Z. Liu (2009), A model study of the effects of winds on concentric rings of gravity waves from a convective plume near Fort Collins on 11 May 2004, J. Geophys. Res., 114, D06103, doi:10.1029/2008JD010753.

Vadas, S., J. Yue, and T. Nakamura (2012), Mesospheric concentric gravity waves generated by multiple convective storms over the North American Great Plain, J. Geophys. Res., 117, D07113, doi:10.1029/ 2011JD017025.

Yuan, T., C.-Y. She, D. A. Krueger, F. Sassi, R. Garcia, R. G. Roble, H.-L. Liu, and H. Schmidt (2008), Climatology of mesopause region temperature, zonal wind, and meridional wind over Fort Collins, Colorado $\left(41^{\circ} \mathrm{N}, 105^{\circ} \mathrm{W}\right)$, and comparison with model simulations, J. Geophys. Res., 113, D03105, doi:10.1029/2007JD008697.

Yue, J., S. L. Vadas, C.-Y. She, T. Nakamura, S. C. Reising, H.-L. Liu, P. Stamus, D. A. Krueger, W. Lyons, and T. Li (2009), Concentric gravity waves in the mesosphere generated by deep convective plumes in the lower atmosphere near Fort Collins, Colorado, J. Geophys. Res. 114, D06104, doi:10.1029/2008JD011244.

Yue J., T. Nakamura, C. Y. She, M. Weber, W. Lyons, and T. Li (2010), Seasonal and local time variability of ripples from airglow imager observations in US and Japan, Ann. Geophys., 28. 